\title{
(2) OPEN ACCESS \\ Double standards in healthcare innovations: the case of mosquito net mesh for hernia repair
}

\author{
Mark Skopec, ${ }^{1}$ Alessandra Grillo, ${ }^{2}$ Alvena Kureshi, ${ }^{2}$ Yasser Bhatti, ${ }^{3}$ \\ Matthew Harris ${ }^{1}$
}

'Department of Primary Care and Public Health, Imperial

College London, London, UK ${ }^{2}$ Department of Orthopaedic and Musculoskeletal Science, University College London, London, UK

${ }^{3}$ School of Business and Management, Queen Mary University of London, London, UK

\section{Correspondence to} Dr Matthew Harris, Department of Primary Care and Public Health, Imperial College London, London SW7 2BU, UK; $\mathrm{m}$. harris@imperial.ac.uk

Received 6 August 2020 Revised 12 November 2020 Accepted 16 November 2020 Published Online First 14 December 2020

\begin{abstract}
With over two decades of evidence available including from randomised clinical trials, we explore whether the use of low-cost mosquito net mesh for inguinal hernia repair, common practice only in low-income and middle-income countries, represents a double standard in surgical care. We explore the clinical evidence, biomechanical properties and sterilisation requirements for mosquito net mesh for hernia repair and discuss the rationale for its use routinely in all settings, including in high-income settings. Considering that mosquito net mesh is as effective and safe as commercial mesh, and also with features that more closely resemble normal abdominal wall tissue, there is a strong case for its use in all settings, not just lowincome and middle-income countries. In the healthcare sector specifically, either innovations should be acceptable for all contexts, or none at all. If such a double standard exists and worse, persists, it raises serious questions about the ethics of promoting healthcare innovations in some but not all contexts in terms of risks to health outcomes, equitable access, and barriers to learning.
\end{abstract}

\section{INTRODUCTION}

There is a growing recognition that health systems in high-income countries (HICs) need to do more with less, and to learn from low-income countries (LICs) that have been doing that for longer. In the UK, the Chief Medical Officer, ${ }^{1}$ Health Education England, ${ }^{2}$ Tropical Health Education Trust (THET) ${ }^{3}$ and a variety of research councils ${ }^{4-6}$ have all taken steps to ensure a more equitable exchange of knowledge between HICs and LICs. In the USA, the National Institutes of Health, ${ }^{7}$ Robert Wood Johnson Foundation ${ }^{8}$ and Fogarty International ${ }^{9}$ are beginning to fund research projects that specifically

\section{Summary box}

What is already known?

- Mosquito net mesh has been used in lowincome countries for many years and there is strong, clinical evidence to suggest that it is as safe and as effective as commercial mesh for inguinal hernia repair.

- Mosquito net mesh is a fraction of the cost of commercial mesh and therefore offers cost-saving opportunities even for high-income country health systems.

What are the new findings?

- Our research finds that mosquito net mesh more closely resembles the biological and mechanical properties of the abdominal wall and therefore more suitable for use in hernia mesh repair.

- The absence of its recommendation for use in high-income settings represents a glaring double standard and is not explained entirely by challenging commercial and regulatory environments.

- Safe and effective innovations should be considered in all settings, not discounted prematurely based on the settings from where they have originated.

focus on opportunities to learn from these contexts. There are clear benefits from adopting often-frugal healthcare innovations that have originated in LIC contexts. ${ }^{10-13}$ One such innovation is the use of small sections of sterilised mosquito-net mesh (MM) for the repair of inguinal hernia (IH), as opposed to commercial mesh (CM). Although this is used at scale in many LICs, at present there is no experience of a hospital in an $\mathrm{HIC}$ using MM for $\mathrm{IH}$ repairs that we can describe.

In this clinical review, we detail the evidence that exists to support efforts for wider adoption of the low-cost MM in 
practice regardless of context. We review the evidence for health outcomes from studies and trials conducted to date, compare the physical and material properties of the commercially available CM with those of the various MMs, and discuss aspects of the process of implementation. Although we find the MM is not identical, it is comparable to CMs in terms of health outcomes. We also find that although there exists vast variation within and across all mesh types, the mechanical properties of the MM are more similar to human abdominal wall tissue than CMs, and therefore may foster a speedier biological adaptation and recovery process. There are many examples of frugal innovations that could surpass performance metrics of costlier incumbent technologies. ${ }^{14}$ While there are challenges to overcome in terms of differences in sterilisation and other institutional practices between contexts, there is sufficient evidence to suggest a more concerted effort could be made to consider adapting this practice all across the world, and not just in low/ middle-income countries (LMICs) just because it is an affordable intervention. $\mathrm{MM}$ has been reported to be 10000 times cheaper than $\mathrm{CM},{ }^{15}$ so the missed opportunity for cost-saving in HIC settings requires close examination to determine the basis to this apparent difference in recommendation. There is increasing interest in reverse innovation, where frugal innovations from LICs have then been adopted in HICs. ${ }^{16}$ To exemplify the relevance of MM in a HIC context, we discuss the policy landscape of the EU and the activities needed to consider wider adoption of using this type of mesh in the UK National Health Service (NHS) given the possible benefits to patients and the UK health system. We recommend that, at the very least, further research on MM in HIC settings is needed, such as collating evidence of health outcomes, carrying out material studies on different types of low-cost mesh as compared with $\mathrm{CM}$, identifying a sustainable supplier, and securing CE marking for use in Europe and elsewhere.

\section{Inguinal hernia (demand/cost/access)}

Worldwide, IH repair is one of the most commonly performed surgeries, with approximately 20 million people undergoing the procedure annually. ${ }^{17}$ The lifetime occurrence of $\mathrm{IH}$ is $27 \%-43 \%$ in men and $3 \%-6 \%$ in women, ${ }^{17}$ though about $98 \%$ of $\mathrm{IH}$ are found in men. ${ }^{18} \mathrm{IH}$ can be treated via open or laparoscopic surgery. Both methods require the insertion of a surgical mesh. The UK National Institute for Clinical Excellence (NICE) recommend the use of laparoscopic surgery for the repair of $\mathrm{IH}$ due to the decreased incidence of long-term pain and numbness, and the possibility of an earlier return to normal activities. ${ }^{18}$

It is estimated that the total cost of open mesh hernia repair to the NHS is approximately $£ 95 \mathrm{M}$ per year. ${ }^{19}$ According to the Royal College of Surgeons (RCS) and the British Hernia Society (BHS), approximately 79
000 surgical repairs of IH were carried out in the NHS in 2016-2017, an increase of $0.8 \%$ compared with $2015-2016 .^{20}$ As the incidence rate of IH increases from 11 per 10000 in men aged $16-24$ to 200 per 10 000 in men aged 75 years and above, ${ }^{21}$ and considering an ageing UK population, the burden of disease for $\mathrm{IH}$ as well as expenditures associated with its treatment is likely to increase in the coming years. NICE estimate that if the annual percentage of laparoscopic repairs (vs open repair) were to increase to $20 \%$, the additional cost to the NHS would amount to $£ 1$ million. ${ }^{18}$ NICE therefore suggest several methods to improve cost effectiveness of the procedure, such as transitioning to reusable equipment ( $£ 170$ per procedure) and away from disposable equipment ( $£ 790$ per procedure). ${ }^{18}$ A 2018 survey conducted by the RCS and the BHS further found that $57 \%$ of Clinical Commissioning Groups (CCGs) that responded had policies in place that restricted access to surgery in order to contain costs. ${ }^{20}$ Fifty-two per cent of CCGs stipulated that evidence of 'sufficient pain and discomfort' was required for surgical intervention to be indicated ${ }^{20}$ suggesting that these restrictive policies have been put into place in a response to acute financial pressures. ${ }^{20}$

COMPARISON BETWEEN COMMERCIAL AND MM Clinical effectiveness, safety, recurrence, relapse, infections rates

The clinical effectiveness of $\mathrm{MM}$ for $\mathrm{IH}$ repair has been widely documented in the literature. Hernia International, a non-profit organisation delivering hernia repair operations throughout sub-Saharan Africa, has conducted over 20000 procedures with non-insecticide treated MM since 2008, without demonstrable impact on adverse events (low-desnity polyethylene MM sourced from AMSA Plastics, India, personal communication with Prof Andrew Kingsnorth). A retrospective analysis by the clinician that first tested the procedure with MM, Ravindranath Tongaonkor, conducted between 1996 and 2002, examined the results of 359 patients across four hospitals in India who underwent IH repair using sterilised MM made of polypropylene and polyethylene copolymer. ${ }^{22}$ Over follow-up ranging from 1 month to 5 years, there was only 1 recurrence $(0.27 \%)$ and infection (caused by stitch abscesses) was observed in 4.7\% of patients. ${ }^{22}$ A 2009 analysis of patients undergoing $\mathrm{IH}$ repair using sterilised polyester MM in Ghana by surgeons with the charity Hernia International found similar results. ${ }^{23}$ Of the 95 patients who underwent surgery, at the 6-week and 6-month follow-up, a total of $7(7 \%)$ had suffered wound complications. ${ }^{23} \mathrm{~A}$ 10 -year retrospective analysis of 615 patients undergoing $\mathrm{IH}$ repair using low-density polyethylene $\mathrm{MM}$ with 12-18 months follow-up reported no recurrences or mesh rejections. Eleven patients experienced postoperative complications all of which were resolved with conservative management. ${ }^{24}$ 
However, single-arm studies provide only limited comparison between $\mathrm{MM}$ and $\mathrm{CM}$ as they often measure different outcomes and do not control for severity of cases. Several randomised controlled trials (RCTs) have been conducted to allow for direct comparison between the two materials. In 2006, Freudenberg et al compared 100\% nylon MM with a $\mathrm{CM}$ in a randomised, double-blind study performed at the University of Ouagadougou in Burkina Faso. ${ }^{25}$ Thirty-five patients with $\mathrm{IH}$ were recruited. ${ }^{25}$ Twenty hernias each were repaired using either $\mathrm{MM}$ or $\mathrm{CM}^{25}$ Study authors measured the difference in preoperative and postoperative quality of life (QOL), as well as the surgeons' judgement of the ease of handling each of the meshes. ${ }^{25}$ In both groups, there was a statistically significant difference in preoperative and postoperative QOL, with no difference in mean outcome between the MM and CM groups. ${ }^{25}$

A 2016 RCT of 302 patients conducted in Uganda found similar results. ${ }^{26}$ Primary outcomes investigated were postoperative complications at 2-week follow-up and hernia recurrence at 1 -year follow-up. ${ }^{26}$ There was one $(0.7 \%)$ recurrence of $\mathrm{IH}$ in the MM group at the 1-year follow-up, with none reoccurring in the $\mathrm{CM}$ group. ${ }^{26}$ Postoperative complications occurred in $30.8 \%$ of patients in MM group, and $29.7 \%$ of patients in CM group. ${ }^{26}$ None of the differences were statistically significant. ${ }^{26}$

A 2002 meta-analysis of RCTs of IH repair with CM comprising a total of 11174 patients found that recurrence of hernia was reported in 88 (2.0\%) of 4426 mesh repairs, comparable performance with that of $\mathrm{MM}^{27}$ Two systematic reviews on this topic further strengthen the findings outlined above. In 2012, Sørensen and Rosenberg concluded that in a total of 577 patients who underwent IH repairs with non-CM (comprising 589 meshes inserted in total; 93\% of those used were MM), $6.1 \%$ had short-term complications (such as infections, or haematomas), and $0.17 \%$ had recurrence. ${ }^{28}$ Patterson et al published the most up-to-date systematic review comparing postoperative adverse effects of MM to CM for IH repair in $2017 .{ }^{29}$ Five studies were included, ranging from 2006 to $2016 .{ }^{29}$ A total of $313 \mathrm{MM}$ and $307 \mathrm{CM}$ were inserted across the 5 studies. ${ }^{29}$ Average study length was 32.1 months (outliers at 6 weeks and 5 years), with follow-up ranging from active follow-up at 2 weeks to passive follow-up at up to 5 years. ${ }^{29}$ There was a total of $74(23.6 \%)$ and $76(24.8 \%)$ adverse events in the $\mathrm{MM}$ and CM groups, respectively. ${ }^{29}$ The overall OR of pooled adverse effects following IH repair using MM was 0.93 (95\% CI 0.63 to 1.35$).{ }^{29}$ The amount and quality of evidence supporting the equivalent efficacy and safety of MM for IH repair as a 'cost-effective alternative to $[\mathrm{CM}]$ for hernia repair' is clear. ${ }^{29}$ Several studies also investigated the ease of handling of $\mathrm{MM}$ by surgeons finding it to be comparable to $\mathrm{CM}^{23}$ and very practical. ${ }^{25}$
Despite the wealth of clinical evidence to suggest comparable outcomes between CM and MM, all of the studies, including the 2018 International Hernia Guidelines, ${ }^{17}$ fall short of explicitly recommending that MM be used in HIC settings, only in LIC settings.

\section{Physical and material properties}

$\mathrm{CMs}$ are made from a variety of materials which commonly include polypropylene, polyethylene or combinations of these. Meshes currently used for hernia repair can be characterised according to their weight (heavyweight and lightweight). These vary in pore size, thickness, tensile strength and stiffness. These properties are important because they will dictate how well the mesh can perform its function to reinforce the tissue and also how it will integrate within the host. The type of material used in MM is often not documented but can be made of nylon or similar materials to $\mathrm{CM}$. As with $\mathrm{CM}$, there are several varieties of MM. Deeken and Lake reviewed the CMs available on the market and summarise their main structural and mechanical properties. ${ }^{30}$ In table 1 and figure 1 , we have summarised these values and compared them with different varieties of MM. ${ }^{31-34}$ This comparison shows that MM tends to exhibit similar pore size and weight to the preferred lightweight $\mathrm{CM}$ currently on the market (figure 1), also demonstrated by Sanders et al..$^{34}$

Weight, thickness and stiffness are important, because together they will determine how flexible or stiff the mesh is. Stiff mesh may be more likely to erode tissue and cause irritation during movement. Tensile strength is important because the mesh needs to resist the intraabdominal pressures exhibited from bending, straining and lifting. In practice, the ideal-type mesh is one that most closely resembles native human tissue. ${ }^{35}$ For IH, this is the transversalis fascia and for ventral hernias this is the posterior rectus sheath; both are connective tissue layers beneath the rectus abdominis muscle.

Table 1 and figure 1 show that although MM is comparable to both lightweight and heavyweight CM in terms of thickness it has a much lower stiffness than either of these, without sacrificing tensile strength and indeed is most comparable to native tissue, compared with commercial alternatives. The increased similarity of $\mathrm{MM}$ to native tissue suggests that MM may provide an advantage over $\mathrm{CM}$ by producing a more favourable biological response. Figure 2 illustrates the comparison of mechanical properties between CM, MM and native tissue. CMs are usually overengineered and are far stronger and stiffer than native tissue. This mismatch in properties may lead to the current complications associated with hernia repair. ${ }^{35}$

\section{Sterilisation standards for mesh}

Depending on the composition of the MM (discussed above), the temperature at which MM can be sterilised without compromising the quality of its properties may 
Table 1 Table showing material, name and values of thickness, ultimate tensile strength, stiffness, pore size and weight for heavyweight, lightweight commercial meshes and mosquito meshes

\begin{tabular}{|c|c|c|c|c|c|c|c|}
\hline Mesh brand & Mesh material & $\begin{array}{l}\text { Pore size } \\
(\mathrm{mm})\end{array}$ & $\begin{array}{l}\text { Weight } \\
\left(\mathrm{g} / \mathrm{m}^{2}\right)\end{array}$ & $\begin{array}{l}\text { Thickness } \\
\text { (mm) }\end{array}$ & $\begin{array}{l}\text { Ultimate } \\
\text { tensile } \\
\text { strength } \\
(\mathrm{N} / \mathrm{cm})\end{array}$ & $\begin{array}{l}\text { Stiffness } \\
\left(\mathrm{N} / \mathrm{mm}^{2}\right)\end{array}$ & Reference \\
\hline \multicolumn{8}{|l|}{ Heavyweight } \\
\hline Parietex (TECR) & Polyester & 2 & 120 & 0.53 & 93 & 66 & $\begin{array}{l}\text { Hollinski et al }{ }^{50} \\
\text { Deeken and Lake }\end{array}$ \\
\hline $\begin{array}{l}\text { Parietex Flat SheeT 2D } \\
\text { Mesh (TEC) }\end{array}$ & Polyester & 2 & $109.6^{*}$ & $0.53^{*}$ & 109 & 57 & $\begin{array}{l}\text { Hollinski et a }\left.\right|^{50} \\
\text { Deeken and Lake }{ }^{30}\end{array}$ \\
\hline Surgipro & Polypropylene & 0.8 & $97^{*}$ & 0.57 & 121 & 45 & $\begin{array}{l}\text { Hollinski et a }\left.\right|^{50} \\
\text { Deeken and Lake }{ }^{30}\end{array}$ \\
\hline Marlex & Polypropylene & 0.46 & 95 & 0.63 & 93 & 3.9 & $\begin{array}{l}\text { Hollinski et } a^{50} \\
\text { Deeken and Lake }{ }^{30}\end{array}$ \\
\hline PROLENE Mesh & Polypropylene & $1.2^{*}$ & $93.8^{*}$ & $0.5^{*}$ & 99 & 14 & $\begin{array}{l}\text { Hollinski et } a^{50} \\
\text { Deeken and Lake }{ }^{30}\end{array}$ \\
\hline Parietene & Polypropylene & $1.3^{*}$ & $77.5^{*}$ & 0.53 & 60 & 10 & $\begin{array}{l}\text { Hollinski et a }{ }^{50} \\
\text { Deeken and Lake }\end{array}$ \\
\hline \multicolumn{8}{|l|}{ Lightweight } \\
\hline ULTRAPRO & $\begin{array}{l}\text { Polypropylene and } \\
\text { polyglecaprone }\end{array}$ & 2.28 & $43^{*}$ & $0.47^{*}$ & 104 & 5.8 & $\begin{array}{l}\text { Hollinski et a }{ }^{50} \\
\text { Deeken and Lake }{ }^{30}\end{array}$ \\
\hline VYPRO II & $\begin{array}{l}\text { Polypropylene and } \\
\text { polyglactin }\end{array}$ & 2.6 & 40 & 0.39 & 71 & 10 & $\begin{array}{l}\text { Hollinski et a }\left.\right|^{50} \\
\text { Deeken and Lake }{ }^{30}\end{array}$ \\
\hline Parietene Light & Polypropylene & $1.6^{*}$ & $37^{*}$ & 0.36 & 40 & 3.6 & $\begin{array}{l}\text { Hollinski et a }{ }^{50} \\
\text { Deeken and Lake }{ }^{30}\end{array}$ \\
\hline TIMESH Light & $\begin{array}{l}\text { Titanium-polypropylene } \\
\text { composite }\end{array}$ & 1.24 & 33 & 0.29 & 21 & 23 & $\begin{array}{l}\text { Hollinski et a }\left.\right|^{50} \\
\text { Deeken and Lake }{ }^{30}\end{array}$ \\
\hline VYPRO & $\begin{array}{l}\text { Polypropylene and } \\
\text { polyglactin }\end{array}$ & 3 & 26 & 0.34 & 88 & 16 & $\begin{array}{l}\text { Hollinski et } a^{50} \\
\text { Deeken and Lake }{ }^{30}\end{array}$ \\
\hline TIMESH ExtraLight & $\begin{array}{l}\text { Titanium-polypropylene } \\
\text { composite }\end{array}$ & 1.24 & 16 & 0.21 & 11 & 17 & $\begin{array}{l}\text { Hollinski et } a^{50} \\
\text { Deeken and Lake }\end{array}$ \\
\hline \multicolumn{8}{|l|}{ Mosquito meshes } \\
\hline India MM & Unknown & 1.5 & 60.1 & na & na & na & Mitura and Kozieł ${ }^{31}$ \\
\hline Ghana MM & Unknown & 2.4 & 49.8 & na & na & na & Mitura and Koziel ${ }^{31}$ \\
\hline Ethiopia MM & Unknown & 2.3 & 41.2 & na & na & na & Mitura and Kozieł ${ }^{31}$ \\
\hline Tanzania MM & Unknown & 2.7 & 35.2 & na & na & na & Mitura and Kozieł ${ }^{31}$ \\
\hline Zambia MM & Unknown & 2 & 31.2 & na & na & na & Mitura and Koziet ${ }^{31}$ \\
\hline Nigeria MM & Unknown & 2 & 15 & na & na & na & Mitura and Kozieł $\left.\right|^{31}$ \\
\hline UK MM1 & Nylon & 1.16 & 34.3 & 0.16 & 27.5 & 0.2 & Grillo et al (unpublished) \\
\hline UK MM2 & Polyester & 2.25 & 29.3 & 0.16 & 22 & 0.12 & Grillo et al (unpublished) \\
\hline MSQ1 & Polyester & na & na & 0.23 & 23.2 & na & Ambroziak et a/33 \\
\hline MSQ2 & Polyester & na & na & 0.20 & 12.8 & na & Ambroziak et $a l^{33}$ \\
\hline MSQ3 & Polyester & na & na & 0.21 & 18.1 & na & Ambroziak et $a{ }^{\beta 3}$ \\
\hline MSQ4 & Polyester & na & na & 0.24 & 21.1 & na & Ambroziak et $a l^{\beta 3}$ \\
\hline Operation hernia MM & Polyethylene & 1.9 & 53.7 & 0.48 & $42.7 \dagger$ & na & Sanders et $a l^{34}$ \\
\hline \multicolumn{8}{|l|}{ Native tissue } \\
\hline Transversalis fascia & & na & na & 0.9 & na & 3 & Kureshi et $a l^{51}$ \\
\hline Posterior rectus sheath & & na & na & 0.09 & 8.5 & na & Anurov et $a l^{52}$ \\
\hline
\end{tabular}

Values of thickness and stiffness of human transversalis fascia are also displayed in the table. ${ }^{51}$ Values of thickness and ultimate tensile strength of posterior rectus sheath are displayed in the table. ${ }^{52}$ Values of pore size, weight and thickness are obtained from Deeken and Lake. ${ }^{30}$

${ }^{*}$ Average calculated from range of values reviewed by Deeken and Lake. ${ }^{30}$ Values of ultimate tensile strength and stiffness were obtained from Hollinski et al. ${ }^{50}$

†Value of ultimate tensile strength of mosquito mesh from Hernia International is in the vertical (warp) direction. ${ }^{34}$

$\mathrm{MM}$, mosquito-net mesh.

vary. ${ }^{22} 296$ The UK Medical Device Agency has established strict guidelines surrounding the sterilisation of medical equipment ${ }^{36}$ and well-recognised European standards require that sterilisation of CM must take place at $134^{\circ} \mathrm{C}$, or if there is a risk of warping, then to sterilise using ethylene oxide (EO), to 'avoid the risk of not destroying agents associated with spongiform encephalopathies' ${ }^{36}$ Stephenson et al compared 
Pore Size - Weight

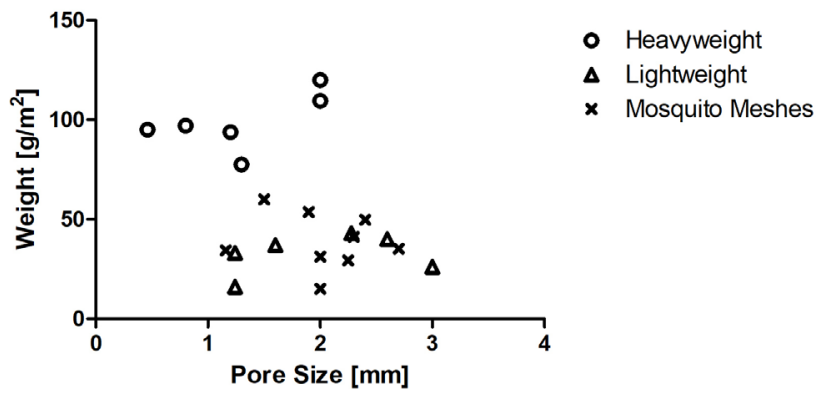

Figure 1 Graph showing correlation between pore size $(\mathrm{mm})$ and weight $\left(\mathrm{g} / \mathrm{m}^{2}\right)$ of heavyweight, lightweight commercial meshes and mosquito meshes. Values of pore size and weight of each mesh are provided in table 1.

the robustness of copolymer MM meshes and meshes made of $100 \%$ polyester autoclaved at $121^{\circ} \mathrm{C}$ and $134^{\circ} \mathrm{C}$, followed by EO sterilisation. ${ }^{36}$ They found that copolymer mesh became hard, shrunken, nonpliable mass following autoclaving at $134^{\circ}$, although at the lower temperature $\left(121^{\circ} \mathrm{C}\right)$, it retained its texture and pliability. It was subsequently used to repair 54 hernias, with no complications reported at 6-month follow-up. ${ }^{36}$ Polyester mesh did not shrink significantly at $134{ }^{\circ} \mathrm{C}$ and no shrinkage occurred in either mesh following EO sterilisation. ${ }^{36}$ Despite polyester mesh's lower proclivity to warping following sterilisation, it does not possess the same handling properties, and was considered less surgeon friendly when compared with the copolymer mesh. ${ }^{36}$ They therefore concluded that MM, whether polyester or copolymer, should be sterilised at $121{ }^{\circ} \mathrm{C} .{ }^{36}$ In their systematic review, Patterson et al conclude that 'although the studies indicated in this review demonstrate the safety profile of [MM] sterilized at $121{ }^{\circ} \mathrm{C}$, it seems unlikely that HICs will change their sterilization policies', as this is a lower sterilisation temperature than that considered acceptable practice in HICs due to the theoretical risk of prion-disease transmission at this lower temperature. ${ }^{29}$ There are two issues that indicate the presence of a possible double standard between practice that is acceptable for HICs and practice that is acceptable for LICs. First, if there is a risk (although unsubstantiated) of prion disease transmission at $121{ }^{\circ} \mathrm{C}$, then is it acceptable to continue to recommend sterilisation at this temperature for MM hernia repair in LICs? It would seem highly unethical to permit the exposure of patients in LICs to even a theoretical risk of prion disease. Second, if MM mesh of all types are stable to sterilisation by EO, a technique which is used and practised in HICs to avoid risk of CM mesh warping, then would it not be entirely possible to substitute CM for $\mathrm{MM}$ in HICs, using $\mathrm{EO}$ sterilisation practice as standard? Neither the potential for using EO sterilisation on MM in HICs nor the inappropriateness of
Ultimate Tensile Strength

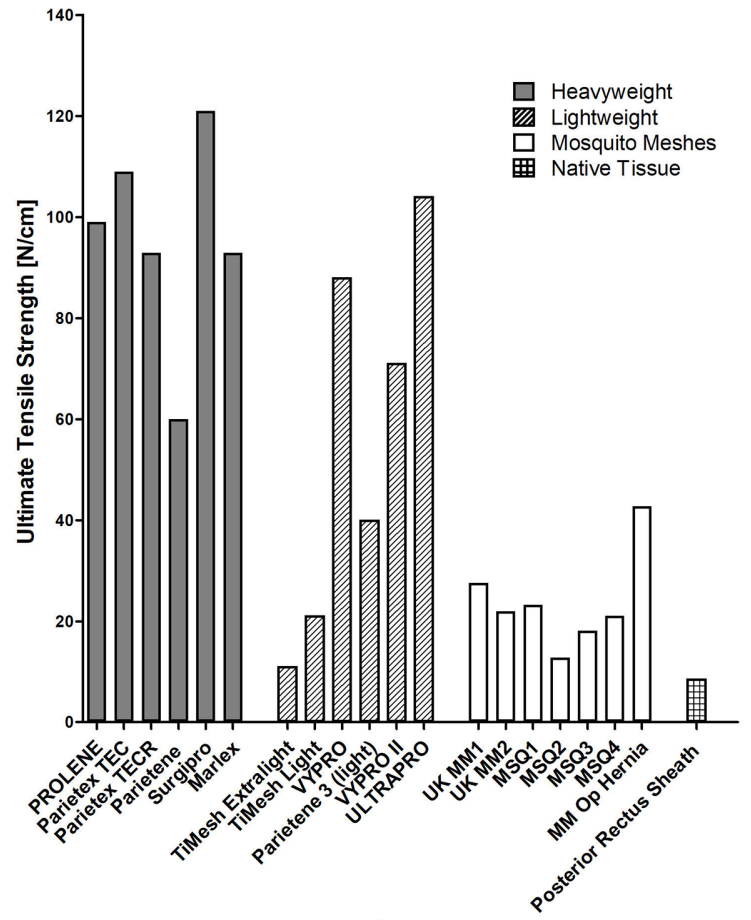

A

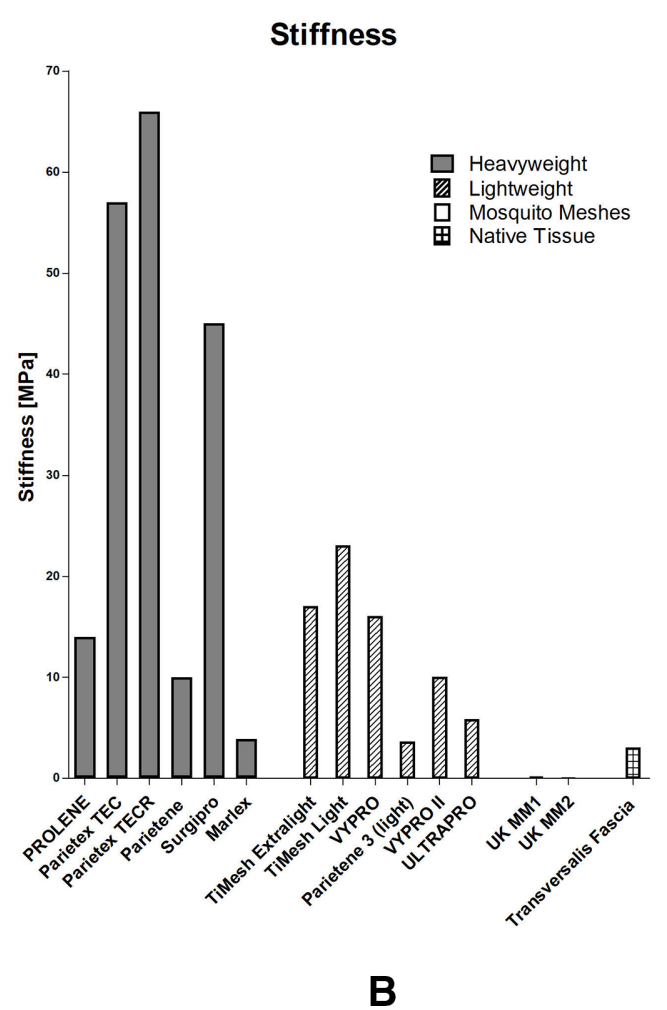


autoclave sterilisation at $121^{\circ} \mathrm{C}$ in LICs for MM have been addressed in any of the literature on MM use for hernia repair to date.

\section{RATIONAL FOR ADOPTION IN HICS \\ Costs associated with the procedure compared with the current best alternative, modelling on possible savings at national and trust level}

The financial imperative for using $\mathrm{MM}$ as opposed to $\mathrm{CM}$ is clear, although the commercial case is complex. Elective repair of IH for adults can cost, in the NHS for instance, between $£ 1458$ and $£ 2607$, depending on the complication and comorbidity score of the patient. ${ }^{37}$ The cost can vary further, depending on the type of procedure (open vs laparoscopic, local vs general anaesthesia) and the type of materials used (single use vs resusable). ${ }^{17}$ NICE estimate the average cost of laparoscopic IH repair to be $£ 1078 .^{18}$ The most commonly used variety of CM in the NHS is Prolene Mesh, at a cost of approximately $£ 300$ per unit. ${ }^{38}$ Other commonly used CMs can cost up to approximately $£ 500$ per unit. ${ }^{39} 40$ Depending on the quantity purchased, prices can vary. For instance, CM commonly costs more than US\$125 (or £100) each when bought in Uganda. ${ }^{26}$ Conversely, the cost of MM can vary greatly depending on the country of origin and the size of the mosquito net from which the mesh is fashioned. ${ }^{29}$ Freudenberg et al calculated the cost of a $10 \times 15 \mathrm{~cm}$ size MM patch to be US $\$ 0.0043,{ }^{25}$ constituting a $7000 \%$ reduction in price compared with CM in the UK. Löfgren et al suggests the MM costs US $\$ 1(£ 0.8)$ in Uganda and Darzi suggest it costs $£ 1.5$ if prepared in the UK. ${ }^{15}{ }^{26}$ The cost of EO sterilisation of MM in the UK is $£ 120$ for an $8 \mathrm{~L}$ bag of MM, corresponding to $£ 0.29$ for the purchase and sterilisation of an $10 \mathrm{~cm} \times 15 \mathrm{~cm}$ unit of MM, not including costs for packaging or distribution. Although the initial cost savings may be small for individual hospitals and trusts, the cost savings accumulated at the national and global levels can be significant. For instance, in the UK, meshes for IH repair alone incur a cost of $£ 2.3$ million, which could be cut to $£ 100000$, a saving of 96 per cent. ${ }^{15}$ Such a price differential could be a challenge to $\mathrm{CM}$ producers, potentially disrupting the market. The extent to which commercial providers are willing to pivot their product to the cheaper MM variety is unknown. It will be important for the reduction in costs to be reflected in the wholesale and retail price point so that savings can be accrued by the system as a whole.

\section{Regulatory environment: CE marking, MHRA, NICE}

In order to be marketed in the UK, a medical device must first obtain CE marking, indicating conformity with the European Union's medical device regulations. ${ }^{41} \mathrm{~A}$ standard $\mathrm{CM}$ is a 'surgically invasive long-term use and implantable device,' and would therefore be classified as a Type IIb device. ${ }^{42}$ Following
CE marking and registration with the Medicine and Healthcare products Regulatory Agency (MHRA), the device can be used in the UK. At this stage, the device may be considered for cost-effectiveness analysis through NICE for procurement. ${ }^{43}$ An additional challenge is the business or commercial consideration for mesh production. There is currently no commercial entity to bear the risk, CE costs and production costs of the MM. Hernia International procures the mosquito nets, prepares and sterilises them through a third-party sterilisation partnership in Eastern Europe and then packages, ships and uses them through charitable donations to the non-governmental organisation (NGO) itself. The viability of $\mathrm{MM}$ as a sustainable offering will depend to some extent on whether or not a commercial, for-profit, social or not-for-profit enterprise, or consortium, will emerge to bear the risk and costs associated with MM use. Notwithstanding this, the clinical cost-effectiveness and biomechanical characterisation of MM compared CM provide for a compelling case at least for this to be explored and developed also in HIC settings. The commercial challenges to using $\mathrm{MM}$ in the UK do not on their own preclude the recognition, at least, of the value of using $\mathrm{MM}$ in the UK context and the need to debate the sterilisation standards that are reasonable to use for MM in the UK and in LICs.

\section{Reverse innovation: policy landscape and advances}

There are few documented innovations developed in LMICs and then adopted for use in HICs - particularly implantable medical devices in the type IIb categorythat have been introduced into the NHS from LICs thus far. There is little established precedent, therefore, for these so-called 'reverse innovations' regarding the procedures that would need to be followed for them to be used in the UK or USA. For instance, there are several exemptions to CE marking that may be applicable, such as exemptions for 'custom-made devices' (MM may qualify as 'custom-made', as each individual mesh would need to be fashioned out of the larger, complete net, and subsequently sterilised ${ }^{44}$ ), and exemptions for 'non-compliant devices used in exceptional circumstances (humanitarian grounds)' (MM was established and is heavily used in humanitarian settings ${ }^{36}$ ). It is therefore unclear if additional CE marking would be required for use in the NHS. ${ }^{44}$ Further, considering the difficult legal terrain, as well as the potential costs associated with protecting the MM through the patenting process, it is possible that this would on the one hand delay the introduction of the devices, and on the other hand increase the price of the final product, reducing its cost effectiveness. Further research is required to fully test and investigate the legal frameworks regarding reverse innovations. This would involve, for example, many other professional and regulatory organisations to ensure successful adoption and diffusion of this MM innovation. In addition to 
registering medical devices with the MHRA, as well as proving cost effectiveness, ideally through a body such as NICE, bodies such as the General Medical Council, the British Medical Association, the RCS and the BHS would need to be consulted for MM to be used clinically. Adoption and diffusion of MM for IH repair will be predicated on the engagement and endorsements of some, if not all these bodies.

There are several barriers to adopting reverse innovations in developed economies, such as the lengthy and expensive process of obtaining CE marking, ${ }^{12}$ the difficulty of identifying innovations for adoption, ${ }^{45}$ as well as bias against innovations and ideas originating from contexts other than our own. ${ }^{46}{ }^{47}$ Despite clearly established safety and effectiveness of MM for $\mathrm{IH}$ repair-evidence supported at the systematic review and meta-analysis level ${ }^{29}$ - the use of MM continues to be promoted in the literature as a solution for $\mathrm{IH}$ repair predominantly in 'resource-scarce, ${ }^{\text {,6 }}$ or 'humanitarian' ${ }^{36}$ settings, or where 'commercial mesh is not available or affordable'. ${ }^{25}$ Such recommendations run counter to the aim of evidence-based medicine of 'systematically locating, appraising and using contemporaneous research findings as the basis for clinical decisions ${ }^{48}$ In the UK, an important first step to using MM in hernia repair has been taken by THET and the Northumbria NHS Trust with their intention to bring MM to the NHS to 'generate significant cost savings without compromising outcomes'. ${ }^{49}$ These advances are encouraging and point to a growing effort to address some of the barriers surrounding global diffusion of innovation.

\section{CONCLUSIONS AND FUTURE RESEARCH}

To avoid double standards, we should consider expanding research on MM in a few key areas. First, further investigation is needed to determine how to source MM centrally and responsibly supply it to the NHS. An organisation with a sustainable business model which supplies and takes on the onus to meet regulatory requirements is needed. Second, a head-tohead clinical trial in the NHS context is required to provide the grade 1 evidence for its cost-effectiveness and efficiency of use. Third, concerns regarding the theoretical transmission of prions through mesh types sterilised at lower temperatures need to be substantiated through microbiological research. $\mathrm{MM}$ has proven to be a cost-effective and safe alternative to CM in LICs. The evidence base suggests that it would be safe and effective in HIC contexts as well. In order to avoid the perpetuation of a double standard, this ultralow-cost alternative to $\mathrm{CM}$ should be adopted into the NHS for IH repair. The theoretical risk of prion disease transmission must be substantiated through adequate microbiological investigation. As Stephenson and Kingsnorth note, although it may be a 'difficult pill for purists to swallow', ${ }^{36}$ it is time to critically reflect on the available evidence on the safety of MM that has accumulated so far, and weigh it against the potential benefits of using this cost-effective surgical method in contexts such as the NHS.

Acknowledgements The authors would like to thank Professor Andrew Kingsnorth for comments made on an earlier draft. $\mathrm{MH}$ is supported in part by the NW London NIHR Applied Research Collaboration. Imperial College London is grateful for support from the NW London NIHR Applied Research Collaboration and the Imperial NIHR Biomedical Research Centre.

Contributors All authors: original concept and design of the study; revision of manuscript and preparation of final draft. MS and $\mathrm{MH}$ : first draft and review of literature. $\mathrm{AG}$ and $\mathrm{AK}$ : analysis of biomechanical data. YB: review and additional of important intellectual content.

Funding The authors have not declared a specific grant for this research from any funding agency in the public, commercial or not-for-profit sectors.

Disclaimer The views expressed in this publication are those of the authors and not necessarily those of the NIHR or the Department of Health and Social Care.

Competing interests None declared.

Patient consent for publication Not required.

Provenance and peer review Not commissioned; externally peer reviewed.

Data availability statement All data relevant to the study are included in the article.

Open access This is an open access article distributed in accordance with the Creative Commons Attribution 4.0 Unported (CC BY 4.0) license, which permits others to copy, redistribute, remix, transform and build upon this work for any purpose, provided the original work is properly cited, a link to the licence is given, and indication of whether changes were made. See: https:// creativecommons.org/licenses/by/4.0/.

\section{REFERENCES}

1 GOV.UK. Chief medical officer annual report 2019: partnering for progress. Available: https://www.gov.uk/government/ publications/chief-medical-officer-annual-report-2019partnering-for-progress [Accessed 13 Aug 2019].

2 Health Education England [Internet]. Improving global health through leadership development programme. Available: https:// www.hee.nhs.uk/our-work/global-engagement/improvingglobal-health-through-leadership-development-programme-0 [Accessed 8 Jan 2020].

3 THET. THET: in our mutual interest. Available: https://www. thet.org/resources/thet-in-our-mutual-interest/ [Accessed 13 Aug 2019].

4 Global Challenges Research Fund. UK Research and Innovation [Internet]. Available: https://www.ukri.org/ research/global-challenges-research-fund/ [Accessed 9 Jan 2020].

5 Medical Research Council MRC. Innovation [Internet], 2014. Available: https://mrc.ukri.org/innovation/ [Accessed 9 Jan 2020].

6 Wellcome [Internet]. Supporting the use of research evidence in policy and practice. Available: https://wellcome.ac.uk/whatwe-do/our-work/supporting-use-research-evidence-policy-andpractice [Accessed 9 Jan 2020].

7 National Institutes of Health (NIH). US and Canada partner to invest \$21 million for research hubs in developing countries, 2015. Available: https://www.nih.gov/news-events/newsreleases/us-canada-partner-invest-21-million-research-hubsdeveloping-countries [Accessed 2 Mar 2020]. 
8 RWJF. Discovering New Ideas [Internet]. Available: https:// www.rwjf.org/en/how-we-work/discovering-new-ideas.html [Accessed 2 Mar 2020].

9 Fogarty International Center Strategic Plan. Advancing Science for Global Health [Internet]. 31 Center Drive, MSC 2220, Bethesda Maryland 20892: National Institutes of Health; 2014 Mar p. 51. Report No: 14-8016 2014.

10 Skopec M, Issa H, Harris M. Delivering cost effective healthcare through reverse innovation. BMJ 2019;367:16205 http://www.bmj.com/lookup/doi/

11 Hayhoe B, Cowling TE, Pillutla V, et al. Integrating a nationally scaled workforce of community health workers in primary care: a modelling study. J R Soc Med 2018;111:45361 http://journals.sagepub.com/doi/

12 Prime M, Attaelmanan I, Imbuldeniya A, et al. From Malawi to Middlesex: the case of the Arbutus drill cover system as an example of the cost-saving potential of frugal innovations for the UK NHS. BMJ Innov 2018;4:103-10 http://innovations. bmj.com/lookup/doi/

13 Macinko J, Harris MJ. Brazil's family health strategydelivering community-based primary care in a universal health system. N Engl J Med 2015;372:2177-81 https://doi.org/

14 Bhatti YA, Prime M, Harris M, et al. The search for the Holy Grail: frugal innovation in healthcare from low-income or middle-income countries for reverse innovation to developed countries. BMJ Innovations 2017;3:212-20 http://innovations. bmj.com/lookup/doi/

15 Darzi A. The cheap innovations the NHS could take from sub-Saharan Africa. The guardian, 2017. Available: https:// www.theguardian.com/healthcare-network/2017/oct/27/cheapinnovations-nhs-take-sub-saharan-africa [Accessed 2 Mar 2020].

16 Harris M, Bhatti Y, Prime M, et al. Low-Cost innovation in healthcare: what you find depends on where you look. J R Soc Med 2018;111:47-50 http://journals.sagepub.com/doi/

17 Simons MP, Smietanski M, Bonjer HJ, et al. International guidelines for groin hernia management. Hernia 2018;22:1165 https://doi.org/

18 Guidance | NICE. Overview | laparoscopic surgery for inguinal hernia repair. Available: https://www.nice.org.uk/ Guidance/TA83 [Accessed 13 Aug 2019].

19 Sharma P, Boyers D, Scott N, et al. Background [Internet]. The clinical effectiveness and cost-effectiveness of open mesh repairs in adults presenting with a clinically diagnosed primary unilateral inguinal hernia who are operated in an elective setting: systematic review and economic evaluation. NIHR Journals Library 2015 https://www.ncbi.nlm.nih.gov/books/ NBK326920/

20 British Hernia Society, Royal College of Surgeons. A dangerous waiting game? A review of patient access to inguinal hernia sugery in England, 2018. Available: rcseng.ac.uk

21 Jenkins JT, O’Dwyer PJ. Inguinal hernias. BMJ 2008;336:26972 http://www.bmj.com/lookup/doi/

22 Tongaonkar RR, Reddy BV, Mehta VK, et al. Preliminary multicentric trial of cheap Indigenous Mosquito-Net cloth for tension-free hernia repair, 2003. Available: https://tspace. library.utoronto.ca/handle/1807/24057 [Accessed 13 Aug 2019].

23 Clarke MG, Oppong C, Simmermacher R, et al. The use of sterilised polyester mosquito net mesh for inguinal hernia repair in Ghana. Hernia 2009;13:155-9.

24 David L, Sanders R. Ten-Year Personal Experience of Using Low Density Polyethylene (LDPE)Mesh for Inguinal Hernia
Repair. Trop Med Surg 2013 https://www.omicsonline.org/ open-access/ten-year-personal-experience-of-using-(ldpe)-meshfor-inguinal-hernia-repair-2329-9088.1000136.php?aid= 18546

25 Freudenberg S, Sano D, Ouangré E, et al. Commercial mesh versus nylon mosquito net for hernia repair. A randomized double-blind study in Burkina Faso. World J Surg 2006;30:1784-9 https://doi.org/

26 Löfgren J, Nordin P, Ibingira C, et al. A randomized trial of low-cost mesh in groin hernia repair. N Engl J Med 2016;374:146-53 http://www.nejm.org/doi/

27 EU Hernia Trialists Collaboration. Repair of groin hernia with synthetic mesh: meta-analysis of randomized controlled trials. Ann Surg 2002;235:322-32 https://www.ncbi.nlm.nih.gov/ pmc/articles/PMC1422456/

28 Sørensen CG, Rosenberg J. The use of sterilized mosquito nets for hernioplasty: a systematic review. Hernia 2012;16:621-5 http://link.springer.com/

29 Patterson T, Currie P, Patterson S, et al. A systematic review and meta-analysis of the post-operative adverse effects associated with mosquito net mesh in comparison to commercial hernia mesh for inguinal hernia repair in low income countries. Hernia 2017;21:397-405 http://link. springer.com/

30 Deeken CR, Lake SP. Mechanical properties of the abdominal wall and biomaterials utilized for hernia repair. J Mech Behav Biomed Mater 2017;74:411-27.

31 Mitura K, Kozieł S. The influence of different sterilization types on mosquito net mesh characteristics in groin hernia repair. Hernia 2018;22:483-90 https://europepmc.org/article/ $\mathrm{med} / 29470735$

32 Grillo A, Hyder Z, Mudera V, et al. In vitro characterisation of low-cost synthetic meshes intended for hernia repair in the UK (forthcoming).

33 Ambroziak A, Szepietowska K, Lubowiecka I. Mechanical properties of mosquito nets in the context of hernia repair. Comput Methods Biomech Biomed Engin 2016;19:286-96 https://doi.org/

34 Sanders DL, Kingsnorth AN, Stephenson BM. Mosquito net mesh for abdominal wall hernioplasty: a comparison of material characteristics with commercial prosthetics. World J Surg 2013;37:737-45 https://doi.org/

35 Zhu L-M, Schuster P, Klinge U. Mesh implants: an overview of crucial mesh parameters. World J Gastrointest Surg 2015;7:226-36.

36 Stephenson BM, Kingsnorth AN. Inguinal hernioplasty using mosquito net mesh in low income countries: an alternative and cost effective prosthesis. BMJ 2011;343:d7448 https://www. bmj.com/content/343/bmj.d7448

37 NHS Improvement. National tariff payment system. Available: Annex-A-National-Prices-And-National-TariffWorkbook.xlsx

38 Aston Pharma. Prolene standard flat mesh heavy weight knitted polypropylene fibre mesh 15CM X 15CM, 2020. Available: https://www.aston-pharma.com/healthcare/prolene-standardflat-mesh-heavy-weight-knitted-polypropylene-fibre-mesh$15 \mathrm{~cm}-\mathrm{x}-15 \mathrm{~cm}$ [Accessed 5 Mar 2020].

39 Aston Pharma. ULTRAPRO mesh UND/BLU 15X15CM. Available: https://www.aston-pharma.com/healthcare/ultrapromesh-undblu-15x15 cm [Accessed 5 Mar 2020].

40 Aston Pharma. VYPRO II mesh UND/VIO 15X15CM. Available: https://www.aston-pharma.com/healthcare/vypro-iimesh-undvio-15x15 cm [Accessed 5 Mar 2020]. 
41 RegDesk. An overview of medical device regulations in the UK. Available: https://www.regdesk.co/overview-medical-deviceregulations-united-kingdom/ [Accessed 15 Jan 2020].

42 Directorate B. Unit B2 "Cosmetics and medical devices." Medical Devices: Guidance document - Classification of medical devices. European Commission 2010.

43 NICE. 7 assessing cost effectiveness | the guidelines manual | guidance | NICE. Available: https://www.nice.org.uk/process/ pmg6/chapter/assessing-cost-effectiveness [Accessed 10 Mar 2020].

44 GOV.UK. Medical devices: conformity assessment and the CE mark. Available: https://www.gov.uk/guidance/medical-devicesconformity-assessment-and-the-ce-mark\#the-ce-marking [Accessed 15 Jan 2020].

45 Harris M, Weisberger E, Silver D, et al. That's not how the learning works - the paradox of Reverse Innovation: a qualitative study. Glob Health 2016;12:36.

46 Harris M, Macinko J, Jimenez G, et al. Measuring the bias against low-income country research: an implicit association test. Global Health 2017;13:1 http://globalizationandhealth. biomedcentral.com/articles/
47 Harris M, Marti J, Watt H, et al. Explicit bias toward HighIncome-Country research: a randomized, blinded, crossover experiment of English clinicians. Health Aff 2017;36:19972004 http://www.healthaffairs.org/doi/

48 Rosenberg W, Donald A. Evidence based medicine: an approach to clinical problem-solving. BMJ 1995;310:1122-6 https://www.bmj.com/content/310/6987/1122

49 Health innovation fellowship programme Lauched. Available: https://www.thet.org/launch-of-our-health-innovationfellowship-programme/ [Accessed 12 Jan 2020].

50 Hollinsky C, Sandberg S, Koch T, et al. Biomechanical properties of lightweight versus heavyweight meshes for laparoscopic inguinal hernia repair and their impact on recurrence rates. Surg Endosc 2008;22:2679-85.

51 Kureshi A, Vaiude P, Nazhat SN, et al. Matrix mechanical properties of transversalis fascia in inguinal herniation as a model for tissue expansion. J Biomech 2008;41:3462-8.

52 Anurov MV, Titkova SM, Oettinger AP. Biomechanical compatibility of surgical mesh and fascia being reinforced: dependence of experimental hernia defect repair results on anisotropic surgical mesh positioning. Hernia 2012;16:199210 https://doi.org/ 